\title{
Home-Based Care for Patients with Lysosomal Storage Disease: Experiences in Argentina
}

Journal of Inborn Errors

of Metabolism \& Screening

2019, Volume 7: e20180002

DOI: 10.1590/2326-4594-JIEMS-2018-0002

\author{
Maria Victoria Brunelli' ${ }^{1}$; Maria Margarita Rabhansl'; Clara Delacre'2; \\ Maria Magdalena Dankert ${ }^{2}$; Maria Victoria Cuevillas'²; Catalina Terán Frias'
}

\begin{abstract}
Enzyme replacement therapy (ERT) is a long term treatment for patients who suffer from lysosomal storage disease. A transversal descriptive study was conducted to evaluate advantages and disadvantages of a home-based care program for patients with Gaucher, Fabry and Mucopolysaccharidosis II (MPS II) diseases. A survey among patients and nurses involved in healthcare delivery at home was utilized for this study. The adherence rate was $92.9 \%$ over the study period. Eighty six point nine percent chose to carry out the treatment at home and $88.5 \%$ felt that their quality of life had improved. Additional advantages reported were: comfort (77\%), treatment adjustment to daily activities (69\%) and flexibility (58\%). Disadvantages expressed were: lack of confidence with the health care provider at home (1.6\%) and a shortage of disposable materials available (1.6\%). The main benefits of home-based treatment were the high treatment adherence and the improvement in quality of life.
\end{abstract}

\section{Keywords}

enzyme replacement therapy, homecare, adherence, Gaucher disease, Fabry disease, Hunter syndrome.

\section{Introduction}

Lysosomal storage diseases (LSD) are progressive genetic disorders that cause a deficiency or the total absence of some enzyme in the lysosome and affects various different organs. Most of these diseases are produced by genetic defects.[1] Among these disorders are Gaucher disease, Fabry disease and Hunter or Mucopolysaccharidosis II (MPS II) disease.

The normal treatment for these LSDs, is enzyme replacement therapy (ERT). This treatment consists of giving the patient an intravenous infusion of a solution containing the deficient enzyme. This type of treatment has been performed for more than 20 years, and numerous studies have demonstrated the safety of ERT.[2-9] Typically, after verifying patient tolerance in the hospital setting according to the protocol for each enzyme, patients who meet the conditions can be a candidate for homebased treatment.[3,4,9-15]

Patients with LSDs note that home-based therapy is less stressful and more convenient than hospital based treatment both for the patient as well as the family.[3,10,13,16-19]

The home-based treatment benefits reported by patients include: the freedom of choosing the date and time for the infusion, $[9,16,18,20]$ the possibility of avoiding the trip to the heath center, $[4,8,11,19-21]$ the oportunity of recieving the infusion in a pleasant and private setting,[16,21] quality of life improvement, $[3,4-6,8,17,21,22]$ possibility to avoid missing a work or a school day, $[3,8,16,19]$ opportunity to decrease the risk of infections which might occur in the hospital,[11] ability to better control the environment,[11] as well as the improvement in the treatment adherence.[3-6,8,10,18,22]

Some of the disadvantages of home-based ERT expressed by patients include the absence of a physian if complications arrise, $[19,21]$ dificulty accessing a vein, $[18,19,21]$ a percieved lesser degree of safety,[19] as well as patients feeling isolated from other individuals in the same situation.[16] Interestingly,

${ }^{1}$ School of Nursing, Universidad Austral, Av Peron 1500. Derqui, Buenos Aires, Argentina

${ }^{2}$ Team Infusion, Buenos Aires, Argentina

Received November 8, 2018. Accepted for publication November 29, 2018.

\section{Corresponding Author:}

Maria Victoria Brunelli, School of Nursing, Universidad Austral, Av Peron 1500. Derqui, Buenos Aires, Argentina.

Email: vbrunell@austral.edu.ar

This article is distributed under the terms of the Creative Commons Attribution 4.0 License (http://www.creativecommons.org/licenses/by/4.0/) which permits any use, reproduction and distribution of the work without further permission provided the original work is attributed as specified on the SciELO and Open Access pages (http://www.scielo.br/revistas/jiems/). 
the professionals who assist these patients consider home-based therapy infusion very beneficial [11] and in addition, it lowers the treatment costs considerably when compared to in hospital treatment.[3,5,6,8,13,16,17,20,21]

Numerous studies regarding home-based ERT for patients with Fabry disease, Gaucher disease and MPS II disease were conducted in England, Holand, Sweeden, Canada, Denmark, France, the United States, [3,8,15,20] Italy [6,22] and Japan.[23] In Argentina, there is some evidence regarding the safety of home infusion in patients who are given algasidase alpha showing only $0.9 \%$ of patients experienced mild adverse effects following infusions.[2] However, another study by Kisinovsky et al. does not provide any information about patients' opinions nor homebased care benefits. Therefore, the objective of our study was to understand and document the advantages and disadvantages of a home-based care program for ERT patients in Argentina.

\section{Methods}

A transversal descriptive study was conducted. The study was designed similarly to that described by Lacely.[24] Data were obtained from patients and health care professionals participanting in the home-base therapy (HBT). These data were triangulated to better understand the phenomenon. Patients receiving care from an in home therapy company in Argentina for the home-based infusion program for ERT during six months in 2016 were analized. All patients included in the study had received at least 4 in home infusions prior to initiating the study. When the patients were underage, their parents or tutor responded to the survey. All of the nursing staff which performed the home-based care for these patients had agreed to be involved in the study.

Two different questionnaires were designed, one targeting the patients and the other aimed at the nursing staff. The surveys were evaluated by a panel of experts and the study was approved by an independent ethics committee. Potential patient participants were contacted by telephone and invited to join the research study. The initial contact was made by a third party individual from the home-based company which reported to the academic institution that is responsible for this research. Those willing to participate were given the questionnaires in a sealed and coded envelope to preserve anonymity and maintain confidentiality.

Data were analyzed using the SPSS software program to find the frequency calculation and central tendency measures for the categorical variables and percentages for the values. To assess the agreement between the patient responses and nurse responses, the Kappa test was used.[24] The adherence rate is expressed as a percentage of the total infusions received over the number of infusions indicated by the infusion protocol used during the six month study period.

Criteria for patient inclusion in the study included: having previously received ERT in the hospital for a number of months (according to the drug and pathology), having no reported adverse reactions to the infusions, posessing a healthy respiratory system and being over 2 years of age.[25]

Patients that reponded to the questionaire and met all the criteria were selected for the study. An infusion protocol based on the specific LSD to be treated was designed for each of the selected patients and was provided to the home-based therapy assistance team. The ERT was administered by a company which employs a nursing team throughout the Country, and is in charge of training professionals in the management and treatment of LSD and has experience providing home-based ERT as well as identifying and managing adverse reactions, etc.

\section{Results}

A total of 125 patients ( $87 \%$ response rate) fully completed the survey and the nursing professionals responded by completing the questionnaire regarding 127 patients. The 127 patients included an additional 2 patients that did not respond directly. Nursing records were also observed from these 127 patients.

The average patient age was 33.23 years old ( $\mathrm{SD} \pm 17.38$ ), with a minimum age of 2 and a maximum age of 80 years old. Within the treated patients, $53.7 \%$ were females and $43.1 \%$ had at least a high school education. Fifty three point zero percent were involved in some kind of occupation (working or studying). Additionally, of the study patients, 70\% were diagnosed with Fabry disease, $13 \%$ with Gaucher disease and 16\% with MPS (Table 1).

The average amount of time in years since patients were first diagnosed with one of the three conditions was 9.6 years (SD \pm 8.4 ), with a maximum of 44 and a minimum of 1 year. The average number of years in total they had been receiving ERT treatment (in hospital and home-based therapy) was 5.4 years (SD \pm 4.8 ). The average number years they had been receiving home-based therapy was $3(\mathrm{SD} \pm 2.3)$. These data are presented in Table 2.

The patients' geographic distribution covered the entire Country of Argentina, ranging from the north of the Country in Tucuman Province to the very southern tip of the Country in Tierra del Fuego Province. A total of 1,601 doses of infusion medication were administered during a six month period. When each disease condition was looked at individually, the average number of infusions for Fabry disease patients was 11.19 in six months, for Gaucher patients it was 10.4 and patients with MPS II received an average of 22.5 infusions during the 6 month study period.

The adherence rate was $92.9 \%$ for all patients. In Table 3 , the number of patients (absolute and percentage) per adherence rate is shown. It can be seen that $88 \%$ of all patients had a compliance rate above $82 \%$.

According to the survey responses, the most frequent reason given for skipping an infusion was "Other Reasons" (48\%), followed by "Lack of Available Medication" (34\%) and finally "Secondary Disease or Illness" (10\%). 
Table 1. Socio-demographic variables of the sample population

\begin{tabular}{|c|c|c|c|}
\hline & & Value & Percentage \\
\hline \multirow{2}{*}{ Sex* } & Female & 66 & 53,7 \\
\hline & Male & 57 & 46,3 \\
\hline \multirow{3}{*}{ Level of Education* } & Primary & 37 & 31,9 \\
\hline & High School & 50 & 43,1 \\
\hline & Tertiary/University & 29 & 25,0 \\
\hline \multirow{6}{*}{ Occupational Status* } & Working & 39 & 33,9 \\
\hline & Studying & 22 & 19,1 \\
\hline & Currently unemployed & 17 & 14,8 \\
\hline & Retired & 13 & 11,3 \\
\hline & Sporadic part-time work & 9 & 7,8 \\
\hline & Other & 15 & 13,0 \\
\hline \multirow{3}{*}{ Diagnostic*** } & Fabry & 89 & 70,1 \\
\hline & Gaucher & 17 & 13,4 \\
\hline & MPS & 21 & 16,5 \\
\hline
\end{tabular}

* These data were obtained from the 125 questionnaires that the patients submitted

***These data were obtained from the 127 questionnaires that the nurses submitted

Table 2. Diagnosis and Treatment Time

\begin{tabular}{lccc}
\hline & $\begin{array}{c}\text { Years of disease } \\
\text { diagnosis }\end{array}$ & $\begin{array}{c}\text { Years of ERT } \\
\text { (hospital and home) }\end{array}$ & Years of home ERT \\
\hline Average & 9.6 & 5.4 & 3.0 \\
Max & 44 & 23 & 12 \\
Min & 1 & 0 & 0 \\
SD & \pm 8.4 & \pm 4.8 & \pm 2.3 \\
\hline
\end{tabular}

Table 3. Frequency of the treatment adherence rate

\begin{tabular}{ccc}
\hline Adherence Rate (\%) & Value & $\%$ \\
\hline 100 & 82 & 65 \\
92 & 18 & 14 \\
88 & 4 & 3 \\
83 & 7 & 3 \\
75 & 4 & 2 \\
71 & 2 & 4 \\
67 & 5 & 2 \\
58 & 3 & 1 \\
33 & 1 & 1 \\
0 & 1 & 100 \\
\hline
\end{tabular}


In our study, 3 patients responded that the main cause for omitting some infusion treatments during an in hospital stay was their reluctance to receive the treatment in the hospital setting, 2 patients missed infusions due to the lack of sufficient beds in the hospital, and there was an additional 2 patients that missed infusions due to secondary disease or illness. Regarding the complete suspension of home-based infusion; 3 patients indicated it was due to secondary disease or illness and 2 patients indicated it was due to travel obligations.

Of the 125 patient respondents in the study, 106 (84.8\%) felt home treatment was more convenient and it did not present significant difficulties to the patient. Moreover, $73 \%$ of the patients indicated that they had no problems communicating with their attending physician throughout the treatment period. Following the home infusion treatment period, $88.5 \%$ considered their quality of life had improved. Ten percent of the patients receiving in home infusion did not feel their quality of life had been affected positively nor negatively and only 1 patient $(0.8 \%)$ indicated that they felt their quality of life had worsened following home infusion.

The most valuable aspect of home infusion treatment noted by the majority of patients (77\%) was that they felt more comfortable receiving therapy in their own home. Furthermore, $69 \%$ indicated that home infusion did not disrupt their daily life activities, 58\% responded that home infusion provided more flexibility in treatment timing, and 56\% indicated that they felt the nurse had more time to dedicate to patient care. Other advantages expressed by patients are shown in Table 4 .
As can be seen in Table 5, only 2 patients (1.6\%) out of the sample expressed negative aspects of in home infusion.

Nurses that performed the in home infusions were consulted regarding their perception of the patient's quality of life and how it may have changed following in home infusion. From the nurses' perspective, they felt that $95.7 \%$ of the patients receiving in home infusion experienced an increase in their quality of life and believed that just one patient's quality of life declined. Nurses who assisted patients with MPS II noticed quality of life improvement to a lesser degree, adding that 1 patient ( $1 \%$ of the total study population) experienced a decline in quality of life.

A Kappa Coefficient of $0.887(\mathrm{p}<0.001)$ was calculated to assess the agreement between the nurses' opinions and the patients' opinions regarding quality of life changes. No statistically significant relationship was found between the years of the illness and the quality of life $(\mathrm{r}=0.71 ; \mathrm{p}=0.44)$ nor between the years of treatment and quality of life $(\mathrm{r}=0.92 ; \mathrm{p}=0.32)$.

In our study, 106 patients (84.8 \%) said they preferred to receive the ERT treatment in their home and 13 patients (10.4\%) indicated that they had no preference between hospital treatment and in-home treatment. The medical professionals' perceptions were similar, with nurses believing that 112 patients (93.3\%) felt there was a benefit to in-home infusion. Regarding the nursing care, it is possible from the questionnaires to understand the issues involving venous access, the amount of spent at the patient's and the difficulties that professionals encounter in carrying out home infusion.

In 124 cases (97.6\%), cannulation was achieved through peripheral venous puncture. When analyzing only the final

Table 4. Advantages of home infusion

\section{Responses}

I feel more comfortable at home

I can adjust the infusion to my daily routine

Timetables are more flexible

The nurse has more time to devote

I travel less to get the infusion

I do not have to wait for availability of beds

I do not miss work or school that often

Total \% of Patients

77

69

58

56

46

31

30

Table 5. Negative aspects of home infusion

\begin{tabular}{lc}
\hline & Total \% of Patients \\
\hline I did not have confidence in the nurse & 1.6 \\
I cannot interact with other patients & 1.6 \\
Disposables are not always available & 1.6 \\
I do not like strangers in my place & 0 \\
It makes me feel uncertain about having some problem with the infusion & 0 \\
\hline
\end{tabular}


home treatment visit, 10 patients $(7.9 \%)$ required more than one attempt when introducing the cannula. Of this group, 8 patients had Fabry disease and 2 patients had MPS II disease.

For in home therapy, $74 \%$ of the patients required a nurse to be present for the procedure for 1 to 2 hours, $8.9 \%$ required 2 to 3 hours, and $4.9 \%$ required a nurse to be present for only one hour. These times included set-up, infusion and any post infusion care. The nursing staff indicated that they did not have difficulties in home assistance in 98 of the cases (81.7\%). However, in 21 cases (17.5\%) nurses noted having occasional difficulties, and noted frequent difficulties with only one patient (0.8\%). Difficulties with the in home therapy procedure reported by the nursing staff are presented in Table 6 . Nurses reported having some difficulty with patients' assistance with the in-home program including; 7 patients not complying with the day and time of the scheduled infusions, 6 patients not organizing and scheduling the time for the next infusion, 6 patients exhibiting emotional fluctuations and in 4 cases the nurses had complications with venous access. There was no overall difference in the occurrence of difficulties across the three pathologies evaluated in this study.

Twelve patients (9.6\%) experienced complications during home infusions and in each of these cases the professionals contacted the home-care company providing the service or the treating physician. When the nursing staff visits the patients, they typically develop a professional relationship with them. Most questions from patients to the nurses were related to the next infusion date and time and any effect the infusions may have on their daily activities. In about half of the cases, patients' inquiries concerned medication they were receiving, status of their illness and what medical check-ups needed to be done (Table 7).

Table 6. Difficulties reported by the nurses during in-home assistance

\begin{tabular}{ll}
\hline & Value \\
\hline Not carrying out scheduled medical check-up & 1 \\
Not assigning the family role & 3 \\
Other & 3 \\
Problems with venous cannulation & 4 \\
Not scheduling the home visit time & 6 \\
Patients exhibiting emotional fluctuations & 6 \\
Not complying with time and date of next infusion & 7 \\
\hline
\end{tabular}

Table 7. Most frequent topics asked to nurses

\begin{tabular}{|c|c|c|c|c|}
\hline Consultation topics & Never (\%) & $\begin{array}{l}\text { Seldom } \\
\text { (\%) }\end{array}$ & $\begin{array}{l}\text { Frequently } \\
\text { (\%) }\end{array}$ & $\begin{array}{c}\text { Very frequently } \\
\text { (\%) }\end{array}$ \\
\hline Appointment scheduling & 8 & 21 & 43 & 27 \\
\hline Daily activities information & 20 & 22 & 37 & 20 \\
\hline Diet information & 32 & 31 & 25 & 12 \\
\hline Medication information & 16 & 36 & 37 & 11 \\
\hline Disease information & 23 & 35 & 32 & 11 \\
\hline $\begin{array}{l}\text { Medical check-ups \& } \\
\text { appointments }\end{array}$ & 30 & 29 & 31 & 11 \\
\hline Paperwork information & 32 & 30 & 28 & 9 \\
\hline Material information & 38 & 30 & 25 & 7 \\
\hline Home conditions information & 51 & 25 & 20 & 4 \\
\hline Other & 0 & 60 & 40 & 0 \\
\hline
\end{tabular}

\section{Discussion}

Home infusion is seen as beneficial for those patients undergoing ERT. The main advantage of home infusion is the high adherence rate and the resulting quality of life improvement for those patients who suffer from LSD. Our study shows that home infusion can be a good strategy that results in excellent clinical outcomes. Elstein et al. showed an adherence rate of 98\% in patients with Fabry disease[4]. Burton et al. found that only 6 out of 92 patients with Mucopolysaccharidosis II who had received home treatment discontinued the infusions[3]. It is clear that the home infusion program significantly improves the 
Journal of Inborn Errors of Metabolism \& Screening

adherence rate[22]. This represents one of the most important benefits for the patients as well as the health care system itself.

Moreover, an important aspect to strengthen the patient's treatment compliance is to take into account their preferences related to the treatment modality. Patients included in this study chose home infusion as the most suitable and desirable; responding that their quality of life improved when they started receiving home infusion. Various studies in the literature indicate similar results. $[13,23]$ For instance, Zimran et al. showed that the patients reported a higher satisfaction with home infusion and their satisfaction was not related to a reduction in anxiety. [13] It should be noted that some authors indicate that in some instances patients prefer hospital treatment as it generates less anxiety and stress.[16] In our study, only one patient out of 125 mentioned a lack of confidence with the nursing professional during in-home treatment as a disadvantage. The role of the health care professional who administers the home infusion is very important. It is critical that they offer support to both the patient and the family and also provide a safe and comfortable environment throughout the process. Indeed, the nursing professional can build a relationship of trust, contributing to the acceptance and success of the procedure.[20] Furthermore, some authors pointed out the importance of establishing a transition period from the hospital setting to the home setting, $[3,8,10,22]$ as well as having an effective system linking the patient's health care hospital team with the home care assistance team.[20] A good relationship between these two groups can contribute to a reduction in the patient's overall anxiety.

Only one patient in our study reported having a decline in quality of life after starting home infusions. However this individual did not mention what the disadvantages of the treatment modality were and when asked about his preference, he said it was the same for him to receive the treatment in the hospital or at home. In addition, two patients reported an improvement in their quality of life after starting home infusion, although found some infrequent disadvantages in this treatment modality.

The ability to continue normal daily life activities, flexibility in infusion scheduling, and the reduction of time needed for infusion treatment were the main advantages expressed by the patients in this study. These factors are of significant importance for those patients with chronic conditions because they require long term treatment and a substantial time commitment.[26] Additionally, the nurses noted that health care professionals dedicated to in home therapy have more time to assist patients, which in turn helps them to build the confidence needed. Another important factor in home care therapy is the patient and family education. [27] With this in mind, nurses requested that their patients inquire about the treatment process and ways that they can participate and support the activities through diet, medication and other lifestyle modifications.

Although treatment omissions were limited, it is important to understand the reasons and to find out why the patients did not properly carry on with the treatment. When reviewing the health professionals' records, it is also interesting to note that the lack of infusion medication vials was one of the limitations to treatment compliance, which is also mentioned by patients as a disadvantage to in home care. Clearly, part of the activities the nursing professional performs during in home care has to do with administrative and management tasks, such as ensuring there are adequate treatment supplies and/or equipment.[22,27] Certainly, this issue in ERT using in home treatment where the patients are distributed over a large geographic area, is indeed a challenge for any health care facilitator. This situation demonstrates the need to have a coordinated team of home assistance professionals focused on the timely delivery of the needed medical resources and the availability of the storage facilities in the home care situation. [20,22]

When a patient contracts an illness or disease not associated with LSD, ERT should be stopped in some cases. This situation is sometimes unavoidable and should be kept in mind when considering the outcomes for each one of the patients. The issue of secondary illness or disease was not a very frequent occurrence in our group of patients however was a factor in the study by Ceravolo[6] and another study conducted by Parini.[10]

The main link in home care therapy is the nursing professional. The home care nurse should meet the requirements for home care assistance which are specific for each LSD and should also be trained in everything related to the ERT infusion as well as how to handle anaphylactic reactions and other health emergencies. [3,8,11,20] The professional nurses involved in this study were continuously receiving training and it is probably for this reason they have not had any major difficulties or problems during home care assistance. In addition, our nursing staff is able to use their consultations with patients to enhance future training programs.

This present study is not without its limitations. First, the main reason for infusion omission found on the questionnaire was "Other". It has not been quantitatively determined nor examined with scientific rigor what patients actually meant when they selected "Other" as a reason for skipping infusions. Further studies are needed to establish what is really involved regarding this suspension reason, with the goal being to increase compliance. Secondly, the concept of quality of life is multidimensional; therefore it is a difficult to determine if quality of life improvement is due exclusively to the infusion modality. Further investigations need to be conducted to compare the patients' quality of life improvement perception between in home ERT versus in hospital ERT, to clearly discriminate the way home health care assistance impacts these patients' quality of life.

\section{Conclusions}

In our study, most patients preferred to receive their ERT treatment at home and believed their quality of life improved with this treatment modality. The high rate of adherence is the main benefit reported. 


\section{Declaration of Conflicting of Interests}

The author(s) received no financial support for the research, authorship, and/or publication of this article.

\section{References}

1. Shire Argentina - Enfermedades de Depósito Lisossomal (EDLs) [Internet]. [cited 2018 Apr 16]. Available from: http://www.shireargentina.com.ar/shire-argentina/ enfermedades-de-deposito-lisosomal.aspx

2. Kisinovsky I, Cáceres G, Coronel C, Reisin R. Home infusion program for Fabry disease: experience with agalsidase alfa in Argentina. Medicina (Buenos Aires). 2013;73(1):31-34.

3. Burton BK, Guffon N, Roberts J, van der Ploeg AT, Jones $\mathrm{SA} ; \mathrm{HOS}$ investigators. Home treatment with intravenous enzyme replacement therapy with idursulfase for mucopolysaccharidosis type II - data from the Hunter Outcome Survey. Mol Genet Metab. 2010;101(2-3):123129. doi:10.1016/j.ymgme.2010.06.011

4. Elstein D, Abrahamov A, Oz A, Arbel N, Baris H, Zimran A.13,845 home therapy infusions with velaglucerase alfa exemplify safety of velaglucerase alfa and increased compliance to every-other-week intravenous enzyme replacement therapy for Gaucher disease. Blood Cells $\mathrm{Mol}$ Dis. 2015;55(4):415-418. doi:10.1016/j.bcmd.2015.09.002

5. Whiteman DA, Kimura A. Development of idursulfase therapy for mucopolysaccharidosis type II (Hunter syndrome): the past, the present and the future. Drug Des Devel Ther. 2017;11:2467-2480. doi:10.2147/DDDT. S139601

6. Ceravolo F, Mascaro I, Sestito S, et al. Home treatment in paediatric patients with Hunter syndrome: the first Italian experience. Ital J Pediatr. 2013;39(1):53. doi:10.1186/18247288-39-53

7. Cox-Brinkman J, Timmermans RGM, Wijburg FA, et al. Home treatment with enzyme replacement therapy for mucopolysaccharidosis type I is feasible and safe. J Inherit Metab Dis. 2007;30(6):984. doi:10.1007/s10545-007-0686-8

8. Finnigan N, Roberts J, Mercer J, Jones SA. Home infusion with Elosulfase alpha $\left(\right.$ Vimizim $\left.^{\mathrm{R}}\right)$ in a UK Paediatric setting. Mol Genet Metab Rep. 2017;14:15-18. doi:10.1016/j. ymgmr.2017.10.012

9. Schiffmann R, Ries M, Timmons M, Flaherty JT, Brady RO. Long-term therapy with agalsidase alfa for Fabry disease: safety and effects on renal function in a home infusion setting. Nephrol Dial Transplant. 2006;21(2):345-354. doi:10.1093/ndt/gfi152

10. Elstein D, Burrow TA, Charrow J, et al. Home infusion of intravenous velaglucerase alfa: experience from pooled clinical studies in 104 patients with type 1 Gaucher disease. Mol Genet Metab. 2017;120(1-2):111-115. doi:10.1016/j. ymgme.2016.08.005

11. Tifft C, Proud V, Levy P, DeMarco K, Nicely H, Turbeville $S$. Enzyme replacement therapy in the home setting for mucopolysaccharidosis VI: a survey of patient characteristics and physicians' early findings in the United States. J Infus Nurs. 2009;32(1):45-52. doi:10.1097/ NAN.0b013e31819228ee

12. Grupo de trabajo de enfermedades poco frecuentes. Guía para el diagnóstico, seguimiento y tratamiento de la mucopolisacaridosis de tipo II (MPS-II) o Enfermedad de Hunter. Arch Argent Pediatr. 2011;109(2):175-181.

13. Zimran A, Hollak CE, Abrahamov A, van Oers MH, Kelly $\mathrm{M}$, Beutler E. Home treatment with intravenous enzyme replacement therapy for Gaucher disease: an international collaborative study of 33 patients. Blood. 1993;82(4):11071109.

14. Zimran A, Pastores GM, Tylki-Szymanska A, et al. Safety and efficacy of velaglucerase alfa in Gaucher disease type 1 patients previously treated with imiglucerase. $A m \mathrm{~J}$ Hematol. 2013;88(3):172-178. doi:10.1002/ajh.23383

15. Barbey F, Livio F. Safety of enzyme replacement therapy. In: Mehta A, Beck M, Sunder-Plassmann G, eds. Fabry Disease: Perspectives from 5 Years of FOS. [Internet] Oxford: Oxford PharmaGenesis; 2006, Available from http://www. ncbi.nlm.nih.gov/books/NBK11617/

16. Milligan A, Hughes D, Goodwin S, Richfield L, Mehta A. Intravenous enzyme replacement therapy: better in home or hospital? Br J Nurs. 2006;15(6):330-333. doi:10.12968/ bjon.2006.15.6.20681

17. Hughes DA, Mlilligan A, Mehta A. Home therapy for lysosomal storage disorders. Br J Nurs. 2007;16(22):13841389. doi:10.12968/bjon.2007.16.22.27768

18. Linthorst GE, Vedder AC, Ormel EE, Aerts JMFG, Hollak CEM. Home treatment for Fabry disease: practice guidelines based on 3 years experience in The Netherlands. Nephrol Dial Transplant. 2006;21(2):355-360. doi:10.1093/ndt/ gfi221

19. Parini R, Pozzi K, Di Mauro S, Furlan F, Rigoldi M. Intravenous enzyme replacement therapy: hospital vs home. Br J Nurs. 2010;19(14):892-898. doi:10.12968/ bjon.2010.19.14.49047

20. Hughes DA, Evans S, Milligan A, Richfield L, Mehta A. A multidisciplinary approach to the care of patients with Fabry disease. In: Mehta A, Beck M, Sunder-Plassmann G, eds. Fabry Disease: Perspectives from 5 Years of FOS. [Internet] Oxford: Oxford Pharma Genesis; 2006, Available from http://www.ncbi.nlm.nih.gov/books/NBK11587/ 
21. Smid BE, Hoogendijk SL, Wijburg FA, Hollak CEM, Linthorst GE. A revised home treatment algorithm for Fabry disease: influence of antibody formation. Mol Genet Metab. 2013;108(2):132-137. doi:10.1016/j.ymgme.2012.12.005

22. Concolino D, Amico L, Cappellini MD, et al. Home infusion program with enzyme replacement therapy for Fabry disease: the experience of a large Italian collaborative group. Mol Genet Metab Rep. 2017;12:85-91. doi:10.1016/j. ymgmr.2017.06.005

23. Migita M, Shimada T, Hayakawa J, et al. Home treatment with enzyme replacement therapy in a 5-year-old girl with type 2 Gaucher disease. Pediatr Int. 2003;45(3):363-365. doi:10.1046/j.1442-200X.2003.01725.x
24. Lacely, A G K. The Research Process in Nursing, 6th Edition. Sixth edition. United States: Wiley Blackwell; 2006

25. Team Infusion. Criterios generales de orientacion sobre la transición de pacientes MPSII a terapia domiciliaria con idusulfasa. 2015.

26. Little C, Gould R, Hendriksz C. The management of children with Hunter syndrome - a case study. Br J Nurs. 2009;18(5):321-322. doi:10.12968/bjon.2009.18.5.40546

27. Puchi Gómez C, Sanhueza Alvarado O. Rol del profesional de enfermería en unidades de hospitalización domiciliaria de hospitales públicos. Revista iberoamericana de educación e investigación en enfermería. 2015;5(1):8-17. 